\title{
A-Type and T-Type Currents Interact to Produce a Novel Spike Latency-Voltage Relationship in Cerebellar Stellate Cells
}

\author{
Michael L. Molineux, ${ }^{\star}$ Fernando R. Fernandez, ${ }^{\star}$ W. Hamish Mehaffey, and Ray W. Turner \\ Hotchkiss Brain Institute, University of Calgary, Calgary, Alberta, Canada T2N 4N1
}

\begin{abstract}
The modification of first-spike latencies by low-threshold and inactivating $\mathrm{K}^{+}$currents $\left(I_{\mathrm{A}}\right)$ have important implications in neuronal coding and synaptic integration. To date, cells in which first-spike latency characteristics have been analyzed have shown that increased hyperpolarization results in longer first-spike latencies, producing a monotonic relationship between first-spike latency and membrane voltage. Previous work has established that cerebellar stellate cells express members of the $\mathrm{K}_{\mathrm{v}} 4$ potassium channel subfamily, which underlie $I_{\mathrm{A}}$ in many central neurons. Spike timing in stellate cells could be particularly important to cerebellar output, because the discharge of even single spikes can significantly delay spike discharge in postsynaptic Purkinje cells. In the present work, we studied the first-spike latency characteristics of stellate cells. We show that first-spike latency is nonmonotonic, such that intermediate levels of prehyperpolarization produce the longest spike latencies, whereas greater hyperpolarization or depolarization reduces spike latency. Moreover, the range of first-spike latency values can be substantial in spanning 20-128 ms with preceding membrane shifts of $<10 \mathrm{mV}$. Using patch clamp and modeling, we illustrate that spike latency characteristics are the product of an interplay between $I_{\mathrm{A}}$ and lowthreshold calcium current $\left(I_{T}\right)$ that requires a steady-state difference in the inactivation parameters of the currents. Furthermore, we show that the unique first-spike latency characteristics of stellate cells have important implications for the integration of coincident IPSPs and EPSPs, such that inhibition can shift first-spike latency to differentially modulate the probability of firing.
\end{abstract}

Key words: $I_{\mathrm{A}} ; I_{\mathrm{T}} ; I_{\mathrm{H}}$; first-spike latency; FSL; synaptic integration; cerebellum; $\mathrm{K}_{\mathrm{v}} 4 ; \mathrm{Ca}_{\mathrm{v}} 3$; stellate cell

\section{Introduction}

Many neurons actively generate long latencies to first spike that are sensitive to the preceding membrane voltage (Byrne et al., 1979; Storm, 1988; Kanold and Manis, 1999). Traditionally, a low threshold and fast inactivating $\mathrm{K}^{+}$current $\left(I_{\mathrm{A}}\right)$ is required. $I_{\mathrm{A}}$ is activated by hyperpolarization and subsequently opposes any membrane depolarization, resulting in a delay to reach firing threshold. In cells expressing $I_{\mathrm{A}}$, the relationship between latency and membrane voltage has been shown to be monotonic, such that greater hyperpolarization causes longer delays to first spike (Shibata et al., 2000; Kanold and Manis, 2005). First-spike latency has been studied in many sensory systems in which the magnitude of a sensory input can be more effectively encoded by action potential timing than through changes in spike frequency (Thorpe et al., 1996; Heil, 2004; Johansson and Birznieks, 2004; VanRullen et al., 2005). In addition to spike timing, $I_{\mathrm{A}}$ has been shown to play an important role in synaptic integration by influ-

Received June 28, 2005; revised 0ct. 5, 2005; accepted 0ct. 5, 2005.

This work was supported by the Canadian Institutes of Health Research (CIHR) (R.W.T.), CIHR Doctoral Studentships (F.R.F., W.H.M.), Province of Alberta Graduate Scholarships (F.R.F., W.H.M.), and an Alberta Heritage Foundation for Medical Research Scientist Award (R.W.T.). We gratefully acknowledge the technical assistance of M. Kruskic and B. E. McKay for comments on this manuscript.

${ }^{*}$ M.L.M. and F.R.F. contributed equally to this work.

Correspondence should be addressed to Ray W. Turner, Hotchkiss Brain Institute, University of Calgary, 3330 Hospital Drive Northwest, Calgary, Alberta, Canada T2N 4N1. E-mail: rwturner@ucalgary.ca.

DOl:10.1523/JNEUROSCI.3436-05.2005

Copyright $\odot 2005$ Society for Neuroscience ～0270-6474/05/2510863-11\$15.00/0 encing the subthreshold membrane properties (Hoffman et al., 1997; Schoppa and Westbrook, 1999). Thus, understanding the intrinsic mechanisms involved in setting first-spike latency is of general relevance to processing in central neurons.

The cerebellum is a motor structure that requires hightemporal resolution to maintain appropriate motor control (Timmann et al., 1999; Kistler et al., 2000). Cerebellar stellate cells are inhibitory interneurons that receive excitatory and inhibitory inputs from parallel fibers and other stellate cells, respectively (Palay and Chan-Palay, 1974; Midtgaard, 1992a,b). By projecting onto Purkinje cell dendrites, stellate cells can modify the output of the cerebellar cortex (Midtgaard, 1992b; Hausser and Clark, 1997; Jorntell and Ekerot, 2002; Mittmann et al., 2005). Indeed, even single spikes in stellate cells have been shown to significantly delay Purkinje cell firing (Hausser and Clark, 1997), revealing the potential impact of stellate cell spike timing. Stellate cells have been shown to express members of the $\mathrm{K}_{\mathrm{v}} 4$ family (Hsu et al., 2003), a channel that often underlies $I_{\mathrm{A}}$. Despite the expression of $I_{\mathrm{A}}$, stellate cells have not been reported to generate firstspike latencies that are sensitive to hyperpolarization (Hausser and Clark, 1997; Carter and Regehr, 2002; Suter and Jaeger, 2004). This would suggest that an inward current working in the subthreshold region could be interacting with $I_{\mathrm{A}}$ to modify firstspike latencies. Previous work has shown that $I_{\mathrm{A}}$ can interact with other subthreshold currents like a transient $\mathrm{Ca}^{2+}$ current $\left(I_{\mathrm{T}}\right)$ and/or a hyperpolarizing activated cation current $\left(I_{\mathrm{H}}\right)$ to influ- 
ence neuronal excitability (Pape et al., 1994; MacLean et al., 2003; Russier et al., 2003).

In the present work, we studied the biophysical mechanisms that regulate first-spike latency in cerebellar stellate cells and its implications on synaptic integration and spike output. We found that stellate cells showed the longest delays to first spike within an intermediate membrane voltage range $(-70$ to $-74 \mathrm{mV})$. Shorter delays to first spike occurred with more negative or positive membrane voltages. Thus, in stellate cells, the relationship between first-spike latency and membrane voltage is nonmonotonic. We also show that this property is established by the specific kinetic and steady-state properties of $I_{\mathrm{A}}$ and $I_{\mathrm{T}}$. Moreover, these interactions have implications for synaptic integration, in that inhibitory inputs can change the probability for EPSPs to evoke spike discharge by shifting first-spike latency.

\section{Materials and Methods}

Animal care. Sprague Dawley rats [postnatal day 14 (P14) to P24] were obtained from Charles River (Saint-Constant, Quebec, Canada), and procedures were conducted according to guidelines approved by the local Animal Care Committee and the Canadian Council for Animal Care.

Electrophysiology. All chemicals were obtained from Sigma (St. Louis, $\mathrm{MO})$ unless otherwise noted. Whole-cell current- and voltage-clamp recordings were obtained using an Axoclamp 2A and a 700A amplifier (Molecular Devices, Union City, CA), respectively, and data were collected with pClamp 8.1 software (Molecular Devices). Tissue slices of the cerebellum were prepared as detailed by McKay et al. (2005). Briefly, artificial CSF was composed of the following (in $\mathrm{mm}$ ): $125 \mathrm{NaCl}, 3.25$ $\mathrm{KCl}, 1.5 \mathrm{CaCl}_{2}, 1.5 \mathrm{MgCl}_{2}, 25 \mathrm{NaHCO}_{3}$, and $25 \mathrm{D}$-glucose preoxygenated by carbogen $\left(95 \% \mathrm{O}_{2}, 5 \% \mathrm{CO}_{2}\right)$ gas. Rats were anesthetized with sodium pentobarbital (MTC Pharmaceuticals, Cambridge, Ontario, Canada), and the cerebellum was removed. Parasagittal tissue slices of $300 \mu \mathrm{m}$ thickness were cut and subsequently transferred to the recording chamber of a Zeiss (Thornwood, NY) Axioskop FS-2 microscope and maintained at $35^{\circ} \mathrm{C}$ as a submerged preparation. Neurons were visualized using differential interference contrast optics and infrared light transmission. All recordings were performed in synaptic blockers that were bath applied after obtaining the initial seal: picrotoxin $(50 \mu \mathrm{M})$, DL-2-amino5-phosphonopentanoic acid $(25 \mu \mathrm{M}), 6,7$-dinitroquinoxolinedione (10 $\mu \mathrm{M}$; Tocris Cookson, Ellisville, MO), and (2S)-3-([(15)-1-(3,4-dichlorophenyl)ethyl]amino-2-hydroxypropyl)(phenylmethyl)phosphinic acid ( $1 \mu \mathrm{M}$; Tocris Cookson). Pipettes had a resistance of 3-6 $\mathrm{M} \Omega$ with access resistance of 6-12 $\mathrm{M} \Omega(80-90 \%$ compensation in voltage clamp). Our internal solution for current-clamp recordings consisted of the following (in mM): $130 \mathrm{~K}$-gluconate, 0.1 EGTA, 10 HEPES, $7 \mathrm{NaCl}, 0.3 \mathrm{MgCl}_{2}, 5$ di-Tris-creatine phosphate, 2 Tris-ATP, and $0.5 \mathrm{Na}-\mathrm{GTP}, \mathrm{pH} 7.3$, with $\mathrm{KOH}$. For all voltage-clamp recordings, TTX (100 nM) was bath applied. For voltage-clamp recordings isolating $I_{\mathrm{A}}$, the internal solution consisted of the following (in mM): $140 \mathrm{KCl}, 5$ EGTA, 10 HEPES, $2.5 \mathrm{MgCl}_{2}$, with 1 $\mathrm{NiCl}_{2}$ and $2 \mathrm{CsCl}$ in the external bath. For voltage-clamp recordings isolating $I_{\mathrm{T}}$, the internal solution consisted of the following (in mM): 100 $\mathrm{CsCl}, 10 \mathrm{EGTA}, 10 \mathrm{HEPES}$, and $3 \mathrm{MgCl}_{2}$, with $2 \mathrm{CsCl}$ in the external bath.

Voltage- and current-clamp analysis. Voltage-clamp analysis consisted of fitting the time course of current inactivation with a single exponential decay function and the steady-state activation and inactivation curves with Boltzmann functions. Analysis of current-clamp data was accomplished using custom software written in MatLab 6.5 (MathWorks, Natick, MA) or IGOR PRO 4.07 (WaveMetrics, Oswego OR) software. Spike threshold was determined through analysis of the voltage derivative. A calculated junctional potential of $11 \mathrm{mV}$ was subtracted from all current-clamp recordings. In voltage clamp, junction potential was not subtracted because the value was small $(\sim 2 \mathrm{mV})$ for internal $\mathrm{KCl}$ and $\mathrm{CsCl}$. Significant differences were assessed using one- or two-way ANOVA using Tukey's honest significant difference criterion. Averaged data are presented as mean \pm SEM.

Simulations. Simulations were constructed in MatLab 6.5 using a fourth-order Runge-Kutta algorithm with a time step $(d t)$ of $0.005 \mathrm{~ms}$ using the following equations:

$$
m_{\infty}=\frac{1}{1+e^{[-(V+35) / 4]}},
$$

$\mathrm{Na}^{+}$current activation.

$$
\frac{d h}{d t}=\frac{-h+h_{\infty}(V)}{\tau_{h s}(V)}
$$

$\mathrm{Na}^{+}$current inactivation.

$$
h_{\infty}=\frac{1}{1+e^{[(V+35) / 4]}},
$$

steady-state $\mathrm{Na}^{+}$current inactivation.

$$
m_{\mathrm{T} \infty}=\frac{1}{1+e^{[-(V+60) / 3]}},
$$

$\mathrm{Ca}^{2+}$ current activation.

$$
\frac{d h_{\mathrm{T}}}{d t}=\frac{-h_{\mathrm{T}}+h_{\mathrm{T} \infty}(V)}{15},
$$

$\mathrm{Ca}^{2+}$ current inactivation.

$$
h_{\mathrm{T} \infty}=\frac{1}{1+e^{[(V+78) / 3.75]}},
$$

steady-state $\mathrm{Ca}^{2+}$ current inactivation.

$$
\frac{d n}{d t}=\frac{-n+n_{\infty}(V)}{0.5},
$$

noninactivating $\mathrm{K}^{+}$current activation.

$$
n_{\infty}=\frac{1}{1+e^{[-(V+35) / 4]}},
$$

steady-state noninactivating $\mathrm{K}^{+}$current activation.

$$
n_{\mathrm{A} \infty}=\frac{1}{1+e^{[-(V+27) / 8.8]}},
$$

inactivating $\mathrm{K}^{+}$current activation.

$$
\frac{d h_{\mathrm{A}}}{d t}=\frac{-h_{\mathrm{A}}+h_{\mathrm{A} \infty}(V)}{15},
$$

inactivating $\mathrm{K}^{+}$current inactivation.

$$
h_{\mathrm{A} \infty}=\frac{1}{1+e^{[(V+68) / 6.6]}},
$$

steady-state $\mathrm{K}^{+}$current inactivation.

The time constant for inactivation of $\mathrm{Na}^{+}$current in the model was voltage dependent and described by a Lorentzian function:

$$
\tau_{h s}(V)=y_{0}+\frac{2 A w}{4 \pi\left(V-V_{c}\right)^{2}+w^{2}},
$$

for $h: V_{\mathrm{c}}=-74, w=28, A=232, y_{0}=-0.15$.

Voltage was integrated according to the following:

$$
\begin{aligned}
C \frac{d V}{d t}= & I_{\mathrm{E}}-g_{\mathrm{Na}} m_{\infty} h\left(V-E_{\mathrm{Na}^{+}}\right)-g_{\mathrm{K}} n\left(V-E_{\mathrm{K}+}\right)-g_{\text {leak }}\left(V-E_{\text {leak }}\right) \\
& -g_{\mathrm{A}} n_{\mathrm{A} \infty} h_{\mathrm{A}}\left(V-E_{\mathrm{Na}^{+}}\right)-g_{\mathrm{T}} m_{\mathrm{T} \infty} h_{\mathrm{T}}\left(V-E_{\mathrm{Ca}^{2+}}\right) .
\end{aligned}
$$

Constants in the model consisted of the following:

$$
C=1.5 \mu \mathrm{F} / \mathrm{cm}^{2} ; E_{\mathrm{Na}+}=45 \mathrm{mV} ; E_{\mathrm{K}+}=-90 \mathrm{mV} ; E_{\text {leak }}=-70 \mathrm{mV} ;
$$


A +
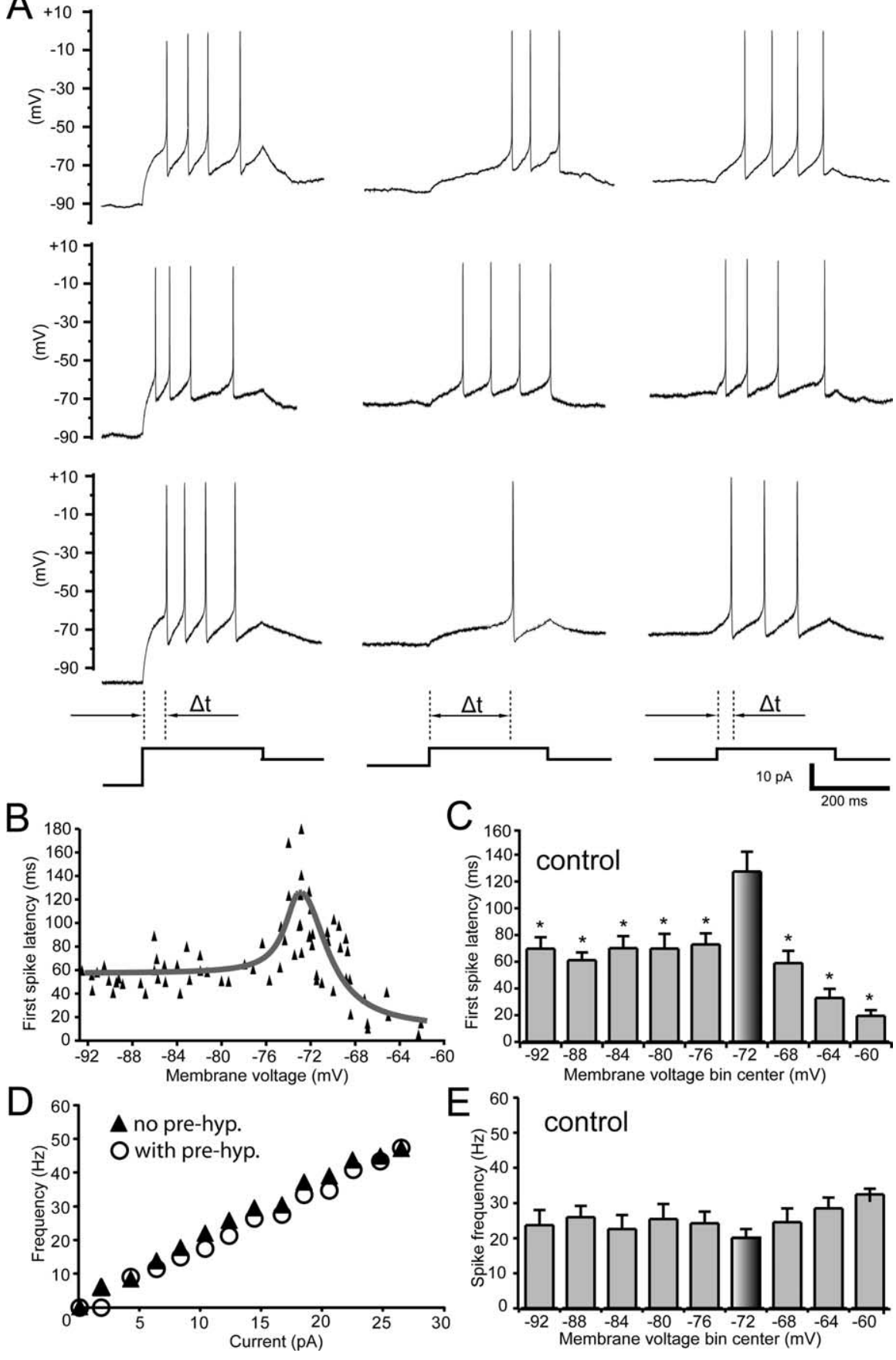

Figure 1. Stellate cells show nonmonotonic first-spike latency characteristics but no rebound burst firing. $A$, Delay to first spike was dependent on the preceding membrane voltage; examples from three different cells are shown. Strong hyperpolarized or depolarized membrane voltage levels resulted in short latencies to first spike (left and right traces), whereas intermediate voltages resulted in the longest latencies (middle traces). Membrane voltage was controlled using hyperpolarizing current steps (bottom traces). $\boldsymbol{B}$, Scatter plot of first-spike latency times over a range of membrane voltages for a representative stellate cell. Spike firing was tested in each case using a weak suprathreshold current step of 5-7 pA after step hyperpolarizations that induced the indicated membrane voltages. $\boldsymbol{C}-\boldsymbol{E}$, Plots showing first-spike latency or firing frequency as a function of preceding membrane voltage using the same current injection protocol as in $\boldsymbol{B}$. All first-spike latency data were first centered within a $4 \mathrm{mV}$ bin of longest delay (shaded bin) and then extended out at $4 \mathrm{mV}$ intervals from this point. The asterisk indicates that bin mean values are significantly different from the longest delay (shaded) bin $(p<0.05)$. C, The latency to first spike showed a nonmonotonic relationship, with the longest delays appearing near $-72 \mathrm{mV}$ ( $4 \mathrm{mV}$ bin width) and shorter delays at voltages above $-70 \mathrm{mV}$ or below $-74 \mathrm{mV}$. D. Representative $F-$ / plot of a stellate cell determined in the presence $(\bigcirc)$ or absence $(\boldsymbol{\Delta})$ of a preceding strong hyperpolarizing pulse (peak, $-90 \mathrm{mV}$ ). The 0 current level corresponds to a return to the original resting level without additional depolarization but with a negative bias current of $15 \mathrm{pA}$. $\boldsymbol{E}$, Spike firing frequency was independent of the preceding membrane voltage under the same recording conditions as in C. Error bars represent SEM.
$E_{\mathrm{Ca} 2+}=22 \mathrm{mV} ; g_{\mathrm{Na}}=30 \mu \mathrm{S} / \mathrm{cm}^{2} ; g_{\mathrm{K}}=7$ $\mu \mathrm{S} / \mathrm{cm}^{2} ; g_{\text {leak }}=0.1 \mu \mathrm{S} / \mathrm{cm}^{2} ; g_{\mathrm{A}}=16 \mu \mathrm{S} / \mathrm{cm}^{2}$; $g_{\mathrm{T}}=0.55 \mu \mathrm{S} / \mathrm{cm}^{2}$.

The conductances for synaptic waveforms were modeled as an $\alpha$ function: $g_{\mathrm{PSP}}(t)=$ $t e^{(-\alpha t)}$, with $\alpha=3$ for EPSP and $\alpha=1.25$ for IPSP and current equal to $I_{\mathrm{E}}(t)=g_{\mathrm{EPSP}}(V)$ and $I_{\mathrm{I}}(t)=g_{\text {IPSP }}(V+82)$.

\section{Results}

Stellate cells show a nonmonotonic first-spike latency-voltage relationship Stellate cells were recorded from the upper half of the cerebellar molecular layer and identified as small cells of 7-10 $\mu \mathrm{m}$ diameter with a multipolar soma that tapered to the primary trunk of small-diameter dendrites $(n=90)$. The input resistance of cells ranged between 500 and $700 \mathrm{M} \Omega$, requiring bath perfusion of synaptic blockers to reduce background membrane fluctuations. In the presence of synaptic blockers, stellate cells spontaneously discharged $\mathrm{Na}^{+}$spikes at a rate of $10-30 \mathrm{~Hz}$. This differs from the activity seen in stellate cells in intact networks in vivo, in which spikes can discharge at a rate of only $\sim 3 \mathrm{~Hz}$ and then primarily in response to synaptic activity (Jorntell and Ekerot, 2003). This study then indicates that stellate cells ordinarily rest at a potential just hyperpolarized enough to allow single EPSPs to trigger spikes. To more closely approximate this activity and compare first-spike latencies, cells were set just below spike threshold using small amounts of bias current (10-20 pA) to establish a quiescent resting membrane ordinarily between -60 and $-65 \mathrm{mV}$. Spike threshold for stellate cells was $-58 \pm 1.4 \mathrm{mV}$ ( $n=14$ ). The resting potential was thus established at a level at which either evoked or simulated EPSPs readily evoked single spike discharge.

Previous immunohistochemical work has shown that stellate cells express $\mathrm{K}_{\mathrm{v}} 4.3$ channels that are known to underlie fastinactivating $\mathrm{K}^{+}$currents $\left(I_{\mathrm{A}}\right)$ (Hsu et al., 2003). To investigate the effects of $I_{\mathrm{A}}$ on first-spike latency, we used hyperpolarizing pulses to vary its availability. Our standard current-clamp protocol consisted of a $500 \mathrm{~ms}$ hyperpolarization followed by a $300 \mathrm{~ms}$ depolarization (Fig. 1A). We found that stellate cells did not respond with an increase in firing frequency following a strong hyperpolarization to -90 $\mathrm{mV}$ (Fig. 1A). Interestingly, the cells did show a dramatic increase in first-spike latency from intermediate hyperpolarized membrane potentials of -70 to $-74 \mathrm{mV}$ (Fig. 1A, middle). This latency was reduced by using either a preceding hyperpolarization or depolarization (Fig. $1 \mathrm{~A}$, 
left and right). To gain a better understanding of the relationship between first-spike latency and membrane voltage, we systematically varied the hyperpolarizing step magnitude from -90 to $-60 \mathrm{mV}$ over the course of 30 current steps. Because the input resistance of stellate cells was very large, the size of the current steps was adjusted for each cell. We used the mean membrane voltage during the $25 \mathrm{~ms}$ preceding the depolarized step to obtain a more accurate estimate of the state of voltage-dependent currents.

Unlike previously described latency plots (Kanold and Manis, 1999; Shibata et al., 2000), our relationship between spike latency and the preceding membrane voltage was nonmonotonic, in which spike latency could be delayed or reduced in a voltagedependent manner (Fig. 1B,C). To quantify the voltage-latency relationship, we created a scatter plot of spike latencies against preceding potentials for each cell (60-120 points per plot) (Fig. $1 B)$. The voltage associated with the longest delay in first-spike latency was established within a sliding $4 \mathrm{mV}$ bin width, identifying a mean voltage of $-72 \mathrm{mV} \pm 1.01(n=12)$ (Fig. $1 C)$. All other data points were then referenced to this mean value and binned at $4 \mathrm{mV}$ increments. As seen in Figure $1 C$, first-spike latency was highly voltage dependent. At membrane voltages of approximately $-72 \mathrm{mV}$, the cells had a maximum latency to first spike of $128 \pm 15 \mathrm{~ms}$, whereas at $-80 \mathrm{mV}$, latency was $70 \pm 10.8$ $\mathrm{ms}$, and at $-60 \mathrm{mV}$, spike latency was $20 \pm 4.1 \mathrm{~ms}$ (Fig. 1C) $(n=$ 12). Additionally, the first-spike latency-voltage relationship was dependent on the basal level of depolarization and excitability of the cell. When the bias current was adjusted such that the cell fired tonically at low frequencies $(1-12 \mathrm{~Hz}$ ), the nonmonotonic first-spike latency relationship was retained (supplemental Fig. $1 A$, available at www.jneurosci.org as supplemental material). When the basal level of excitability was adjusted to allow for tonic high-frequency firing $(>20 \mathrm{~Hz})$, the nonmonotonic first-spike latency relationship was abolished (supplemental Fig. $1 \mathrm{~B}$, available at www.jneurosci.org as supplemental material). We note that in vivo recordings from stellate cells suggest that these cells most often discharge spontaneously in the low-frequency range in the presence of synaptic inputs and do not support regular tonic high-frequency firing (Ekerot and Jorntell, 2001; Jorntell and Ekerot, 2003). The higher basal level of excitability that allows for tonic firing of stellate cells may simply be a phenomenon of the in vitro preparation. The nonmonotonic voltage-latency relationship observed here is thus expected to be active under physiological conditions.

To fully assess the range of stellate cell output, we extended the protocol to include progressively larger depolarizing steps, thereby assessing the effects of a preceding hyperpolarization to approximately $-90 \mathrm{mV}$ on a full frequency-current $(F-I)$ plot of stellate cell output. This established that the $F-I$ relationship was linear, with a firing range between 5 and $50 \mathrm{~Hz}$ that was not affected by the presence or absence of a preceding hyperpolarization (Fig. 1D). A reduction in first-spike latency from hyperpolarizing voltages might be expected to be accompanied by an increase in firing frequency after the generation of a rebound burst. This, however, did not occur in stellate cells, because firing frequency did not change significantly as a function of preceding membrane voltage (Fig. $1 E)(p=0.4 ; n=12)$.

Long delays to first-spike latency are consistent with the presence of a fast-inactivating $\mathrm{K}^{+}$current (Byrne et al., 1979; Storm, 1988). However, a reduced first-spike latency following strong hyperpolarization suggested the interaction of an additional inward subthreshold current, which could include $I_{\mathrm{T}}$ or $I_{\mathrm{H}}$. To first test for the presence of $I_{\mathrm{A}}$ in stellate cells, we bath applied 4-AP at
$6 \mathrm{~mm}$, a concentration shown to block a wide spectrum of A-type $\mathrm{K}^{+}$currents (Coetzee et al., 1999), and performed the same protocol and analysis as in Figure 1, $A-C$. The application of 4-AP significantly decreased first-spike latency from controls and eliminated the nonmonotonic spike latency relationship (Fig. 2A, $B$ ) $(p<0.05)$. The latency values were also now uniform, ranging from 26 to $33 \mathrm{~ms}$, and not significantly different from the -72 $\mathrm{mV}$ bin that originally distinguished the shift from short to long first-spike latencies ( $p=0.78 ; n=5$ ) (Fig. $2 B$ ). Surprisingly, 4-AP still did not unmask a rebound burst, because firing frequency after the hyperpolarization remained independent of the preceding membrane voltage (data not shown). However, the application of 4-AP did increase baseline firing frequency, suggesting that $I_{\mathrm{A}}$ contributed a window current sufficiently depolarized to influence baseline firing frequency. The ability to fire spikes after a hyperpolarization in the presence of 4-AP was also transient, with spike firing terminating before the end of the excitatory current pulse (Fig. $2 \mathrm{~A}$ ). We reasoned that this was because of the very high frequency of spike firing $(>100 \mathrm{~Hz})$, which could elicit a large hyperpolarization through $\mathrm{Ca}^{2+}$-activated $\mathrm{K}^{+}$ currents. This indicated that the 4-AP-sensitive current had some baseline contribution to steady-state firing frequency.

We also considered that 4-AP may block other nontransient $\mathrm{K}^{+}$currents, which could change our interpretation of the above results. To test this, we voltage clamped stellate cells and separated the inactivating and noninactivating $\mathrm{K}^{+}$currents (Fig. 3) (see below for additional details). We found that $6 \mathrm{~mm} 4$-AP produced a substantial block of a fast-inactivating $\mathrm{K}^{+}$current ( $35 \pm 4.6 \%$ reduction; $p<0.05 ; n=5$ ) but did not significantly block noninactivating $\mathrm{K}^{+}$currents $(8 \pm 3.5 \%$; $p>0.05)$. Thus, the effects of $6 \mathrm{~mm} 4$-AP on first-spike latency in stellate cells can be primarily attributed to $I_{\mathrm{A}}$.

Although there are no well established specific blockers for $I_{\mathrm{T}}$, we attempted to block $I_{\mathrm{T}}$ under current-clamp conditions using mibefradil at $500 \mathrm{nM}$, which has been shown to specifically block $I_{\mathrm{T}}$ in Purkinje cells (McDonough and Bean, 1998). Mibefradil eliminated the nonmonotonic first-spike latency characteristic of stellate cells, resulting in a graded increase in first-spike latency with the magnitude of a preceding hyperpolarization (Fig. 2C,D). First-spike latency values now ranged from $187 \pm 17 \mathrm{~ms}$ with a preceding membrane voltage of $-92 \mathrm{mV}$ to $30 \pm 3 \mathrm{~ms}$ with a preceding membrane voltage of $-60 \mathrm{mV}$. Furthermore, the firstspike latencies generated with preceding membrane voltages from -92 to $-84 \mathrm{mV}$ were significantly different from those generated in the control $(p<0.05 ; n=5)$. This result is consistent with mibefradil blocking $I_{\mathrm{T}}$, which would isolate $I_{\mathrm{A}}$ in the subthreshold region and lead to membrane hyperpolarizations inducing a more conventional monotonic increase in first-spike latency.

It is well established that a hyperpolarization-activated cationic current $\left(I_{\mathrm{H}}\right)$ can be recruited at negative voltages to increase cell excitability (Pape, 1996). Such a profile of recruitment could then help account for the shorter latencies observed after strong hyperpolarizations. To test whether $I_{\mathrm{H}}$ was involved in setting the first-spike latency relationship in stellate cells, we bath applied 4-(N-ethyl- $N$-phenylamino)-1,2-dimethyl-6-(methylamino)pyrimidinium chloride (ZD 7288; $10 \mu \mathrm{M}$ ) (Fig. 2 E). Application of ZD 7288 uniformly increased the first-spike latency at all voltages by $18.9 \pm 3.6 \mathrm{~ms}(n=11)$ and eliminated the characteristic hyperpolarization activated membrane voltage sag associated with $I_{\mathrm{H}}$. It did not, however, alter the nonmonotonic first-spike latency-voltage relationship when compared with control data $(p=0.87)$. Furthermore, the preceding membrane voltage that 


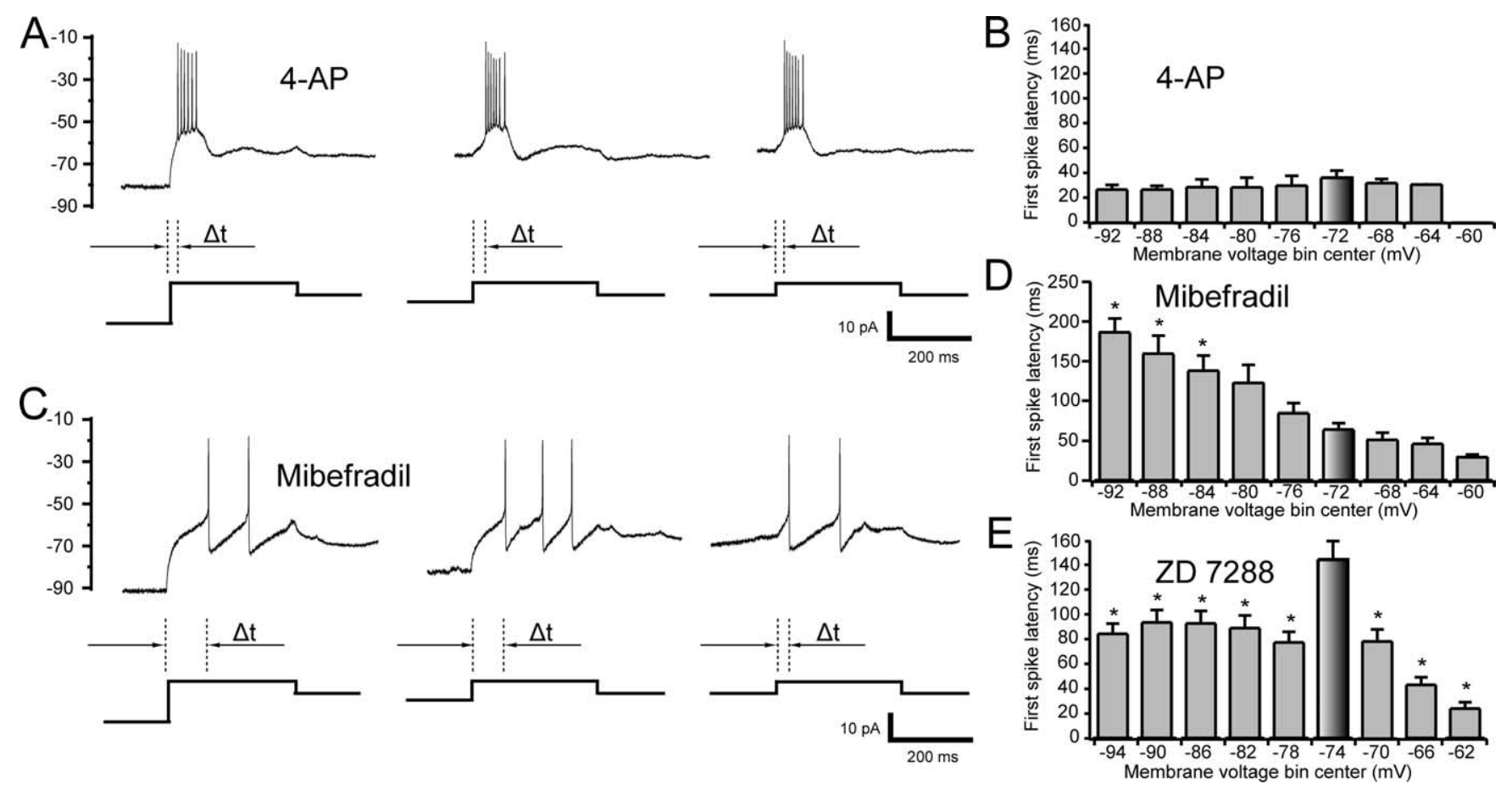

Figure 2. The nonmonotonic first-spike latency of stellate cells is sensitive to 4-AP and mibefradil. $A$, Recordings of first-spike latency tests in a representative cell in the presence of 4-AP (6 mM). $B$, Plot showing latency to first spike as a function of preceding membrane voltage in the presence of 4-AP. The $\mathrm{K}^{+}$channel blocker 4-AP significantly reduced the first-spike latency at all preceding membrane voltages. $\boldsymbol{C}$, Recordings of first-spike latency tests from a representative cell in the presence of mibefradil ( $500 \mathrm{~nm})$. $\boldsymbol{D}$, Plot showing first-spike latency as a function of preceding membrane voltage in the presence of mibefradil. The $I_{T}$ blocker mibefradil eliminates the nonmonotonic shape of the first-spike delay at hyperpolarized preceding membrane voltages. $\boldsymbol{E}$, Plot showing first-spike latency as a function of preceding membrane voltage in the presence of ZD $7288(10 \mu \mathrm{M})$. The $I_{H}$ blocker ZD 7288 uniformly increases first-spike latency for all membrane voltages but does not alter the nonmonotonic relationship. All first-spike latency data in $\boldsymbol{B}, \boldsymbol{D}$, and $\boldsymbol{E}$ were first centered within a $4 \mathrm{mV}$ bin of longest delay (shaded bin) and then extended out at $4 \mathrm{mV}$ intervals from this point. The asterisk indicates that bin mean values are significantly different from the longest delay (shaded) bin ( $p<0.05)$. Error bars represent SEM.

produced the longest first-spike latency did not significantly change (control, $-72 \pm 1.1 \mathrm{mV}$ vs $\mathrm{ZD} 7288,-74 \pm 1.9 \mathrm{mV} ; p=$ 0.19 ) (Fig. $2 E$ ). Thus, $I_{\mathrm{H}}$ can uniformly modify first-spike latency times but is not involved in setting the nonmonotonic first-spike latency profile of stellate cells.

These data establish that first-spike latency of stellate cells is determined in large part through an interplay between $I_{\mathrm{A}}$ and $I_{\mathrm{T}}$. These currents share the property of exhibiting overlapping activation and inactivation curves that establish window currents to precisely regulate their availability over a voltage range near resting potential. The nonmonotonic relationship between membrane voltage and first-spike latency must then reflect the balance between $I_{\mathrm{A}}$ and $I_{\mathrm{T}}$ activation according to their specific voltagedependent kinetic and steady-state properties. A key prediction to explain the decrease in spike latency found with prestep voltages more negative than $-72 \mathrm{mV}$ would be a relatively greater deinactivation of $I_{\mathrm{T}}$ relative to $I_{\mathrm{A}}$. Thus, to further investigate the role of $I_{\mathrm{A}}$ and $I_{\mathrm{T}}$ in producing first-spike latency characteristics, we performed voltage-clamp analysis and then modeling to test whether differences in channel kinetics could account for the experimental data.

\section{Biophysical characterization of $I_{\mathrm{A}}$ and $I_{\mathrm{T}}$}

To confirm the presence of $I_{\mathrm{A}}$ and $I_{\mathrm{T}}$ and determine their biophysical parameters, we used whole-cell voltage clamp and isolated the currents pharmacologically and electrophysiologically. To isolate $I_{\mathrm{A}}$, we bath applied TTX $(100 \mathrm{nM}), \mathrm{Ni}^{2+}(1 \mathrm{mM})$, and $\mathrm{Cs}^{+}(2 \mathrm{~mm})$ or ZD $7288(10 \mu \mathrm{M})$. In all voltage-clamp recordings, synaptic blockers were used to increase cell input resistance and reduce spontaneous activity that contaminated current traces.
These experiments revealed two classes of $\mathrm{K}^{+}$currents, a lowthreshold and fast-inactivating current consistent with $I_{\mathrm{A}}$ and a higher-threshold and noninactivating delayed rectifier. $I_{\mathrm{A}}$ was insensitive to $20 \mathrm{~mm}$ tetraethylammonium (TEA) but blocked with 4 -AP at concentrations $>4 \mathrm{~mm}(35 \%$ block at $6 \mathrm{~mm})$ and completely blocked with $20 \mathrm{~mm}$ 4-AP. However, we found that long-term recordings with $20 \mathrm{~mm} 4$-AP had negative effects on cell health. Thus, to isolate $I_{\mathrm{A}}$, we used a $1 \mathrm{~s}$ depolarizing voltage step to $-45 \mathrm{mV}$, which inactivated $>95 \%$ of $I_{\mathrm{A}}$, and subtracted this record from control traces that used a prevoltage step of $-100 \mathrm{mV}$. Our voltage-clamp protocol consisted of step depolarizations from -100 to $30 \mathrm{mV}$ in $10 \mathrm{mV}$ increments and were followed by a test pulse to $0 \mathrm{mV}$ to determine the steady-state inactivation curve. $I_{\mathrm{A}}$ started activating between -70 and -60 $\mathrm{mV}$ with peak current ranging from $500 \mathrm{pA}$ to $5 \mathrm{nA}($ at $0 \mathrm{mV})$ and showed rapid inactivation (Fig. $3 A$ ). Activation was very fast, with time to peak ranging from 0.8 to $2.5 \mathrm{~ms}$. The conductancevoltage relationship was fit with a Boltzmann function and had a $V_{1 / 2}$ of $-27 \pm 3.0 \mathrm{mV}$ and a slope factor of $10.4 \pm 1.1(n=7)$. The steady-state inactivation curve had a $V_{1 / 2}$ of $-68.2 \pm 1.2 \mathrm{mV}$ and a slope factor of $5.1 \pm 0.5 \mathrm{mV}(n=9)$ (Fig. $3 B)$. The combination of these factors produced a small window current for $I_{\mathrm{A}}$ between -60 and $-40 \mathrm{mV}$, which, in conjunction with the high density of expression in stellate cells, explains why the application of $6 \mathrm{mM}$ 4 -AP increased baseline firing frequency, as shown in Figure $2 \mathrm{~A}$.

To isolate $I_{\mathrm{T}}$, we used TTX and $\mathrm{Cs}^{+}$in the external medium to block $I_{\mathrm{Na}}$ and $I_{\mathrm{H}}$, respectively, and used intracellular Cs ${ }^{+}$to block $\mathrm{K}^{+}$currents. Our voltage-clamp protocol consisted of step depolarizations from -120 to $-30 \mathrm{mV}$ in $10 \mathrm{mV}$ increments. Under these conditions, we observed a low-threshold and fast- 

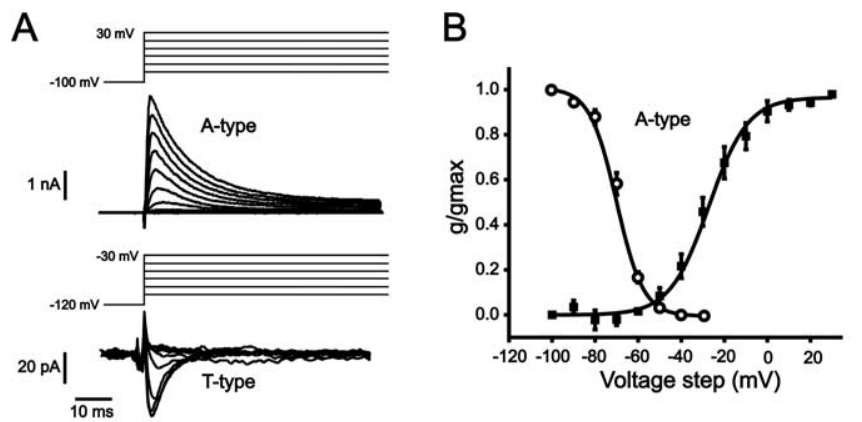

C

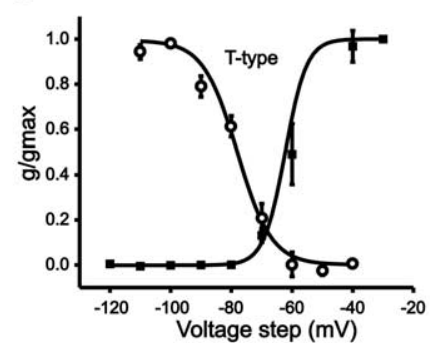

E

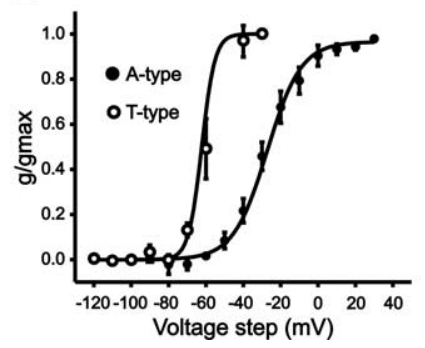

D

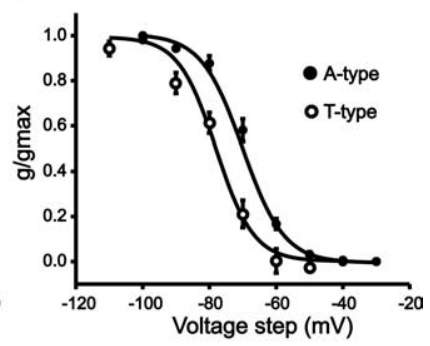

F

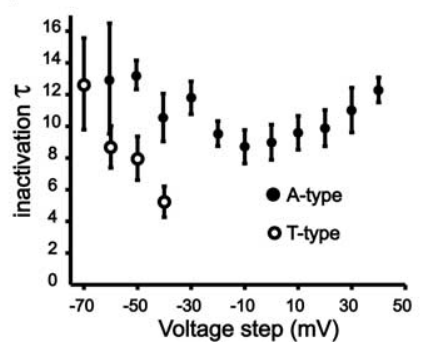

Figure 3. Biophysical parameters of $I_{\mathrm{A}}$ and $I_{\mathrm{T}}$ in cerebellar stellate cells. $\boldsymbol{A}$, Representative whole-cell voltage-clamp traces of $I_{\mathrm{A}}$ (top) and $I_{\mathrm{T}}$ (bottom). For $I_{\mathrm{A}}$ recordings, stellate cells were held at $-100 \mathrm{mV}$ and stepped to $30 \mathrm{mV}$ in $10 \mathrm{mV}$ increments for $1 \mathrm{~s}$, whereas for $I_{\mathrm{T}}$ recordings, cells were held at $-120 \mathrm{mV}$ and stepped to $-30 \mathrm{mV}$ in $10 \mathrm{mV}$ increments for $200 \mathrm{~ms}$. B, C, Steady-state activation $(\square)$ and inactivation $(O)$ plots for $I_{A}(\boldsymbol{B})$ and $I_{\mathrm{T}}(\boldsymbol{C})$. All steady-state plots were fit with Boltzmann functions to derive $V_{1 / 2}$ and $k$ values. The voltage-clamp protocols for activation were the same as in $A$. For inactivation, a test pulse $\left(0 \mathrm{mV}\right.$ for $I_{A} ;-40 \mathrm{mV}$ for $\left.I_{\mathrm{T}}\right)$ was provided following the conditioning voltage steps to measure the available conductance. $\boldsymbol{D}, \boldsymbol{E}$, Comparison of steady-state inactivation $(\boldsymbol{D})$ and activation $(\boldsymbol{E})$ plots for $I_{\mathrm{A}}(\boldsymbol{O})$ and $I_{\mathrm{T}}(\bigcirc)$. Note that $I_{T}$ has more negative steady-state parameters for activation and inactivation and a larger window current than $I_{\mathrm{A}}$. $\boldsymbol{F}$, Inactivation time constant-voltage plots for $I_{\mathrm{A}}$ and $I_{\mathrm{T}}$. The inactivation time course was fit with a single exponential decay function. The voltage-clamp protocol was the same as in $\boldsymbol{A}$. Note that, at voltages near threshold ( -60 to $-70 \mathrm{mV}), I_{\mathrm{A}}$ and $I_{\mathrm{T}}$ have similar inactivation time constants. Because of contamination from a high-threshold $\mathrm{Ca}^{2+}$ current at voltages above $-30 \mathrm{mV}$, the inactivation time course for $I_{\mathrm{T}}$ was restricted to voltages below this value.

inactivating $\mathrm{Ca}^{2+}$ current that activated at approximately -80 $\mathrm{mV}$ (Fig. $3 A, C$ ) and was insensitive to bath application of the dihydropyridine nifedipine $(1 \mu \mathrm{M})$. Peak $I_{\mathrm{T}}$ in the $I-V$ plot was seen between -50 and $-40 \mathrm{mV}$ and ranged from -20 to $-80 \mathrm{pA}$. Like $I_{\mathrm{A}}, I_{\mathrm{T}}$ showed rapid activation kinetics with time to peak ranging from 1.7 to $3.8 \mathrm{~ms}$. At voltages more positive than -30 $\mathrm{mV}$, a second slower and noninactivating $\mathrm{Ca}^{2+}$ current was observed in most cases. Because of the large discrepancy in the activation voltage between the two $\mathrm{Ca}^{2+}$ currents, we could restrict our voltage-clamp protocol to the lower-voltage range to activate $I_{\mathrm{T}}$ in isolation. The activation- and inactivation-voltage relationships were fit with a Boltzmann function. The activation curve had a $V_{1 / 2}$ of $-57 \pm 3.3 \mathrm{mV}$ and a slope factor of $5.3 \pm 1.1$ $(n=6)$, whereas the inactivation curve had a $V_{1 / 2}$ of $-77.6 \pm$
$0.73 \mathrm{mV}$ and a slope factor of $4.7 \pm 0.4(n=7)$. Note that the steady-state inactivation curve for $I_{\mathrm{T}}$ was negatively shifted compared with that of $I_{\mathrm{A}}$ by $\sim 10 \mathrm{mV}$ (Fig. 3D) $\left(I_{\mathrm{A}},-68.2 \pm 1.2 \mathrm{vs} I_{\mathrm{T}}\right.$, $-77.6 \pm 0.73 \mathrm{mV} ; p<0.05)$ and that the conductance-voltage relationship was more negative and steeper for $I_{\mathrm{T}}$ than $I_{\mathrm{A}}$ (Fig. $3 E$ ). Thus, a hyperpolarizing current pulse causing a membrane voltage shift more negative than $-72 \mathrm{mV}$ recruits more $I_{\mathrm{T}}$ relative to $I_{\mathrm{A}}$ and as a result may decrease first-spike latency.

We also characterized the inactivation time constant-voltage relationship for both $I_{\mathrm{A}}$ and $I_{\mathrm{T}}$, because this parameter could play an important role in influencing the latency to first spike in cells (Storm, 1988). With both currents, the inactivation profile was accurately fit with a single exponential decay function. The inactivation time constants for $I_{\mathrm{A}}$ showed weak voltage dependence with values ranging from $13.2 \mathrm{~ms}$ at $-60 \mathrm{mV}$ to $8.8 \mathrm{~ms}$ at $-10 \mathrm{mV}$ (Fig. $3 F$ ). Conversely, the inactivation time constants for $I_{\mathrm{T}}$ showed a slightly stronger voltage dependence with values ranging from $12.7 \mathrm{~ms}$ at $-70 \mathrm{mV}$ to $5.2 \mathrm{~ms}$ at $-40 \mathrm{mV}$ (Fig. $3 F$ ). Note, however, that the inactivation time constants for both currents approached one another $(9-16 \mathrm{~ms})$ at hyperpolarized potentials and were not significantly different at $-60 \mathrm{mV}$ (Fig. $3 F$ ). Thus, at voltages just below the firing threshold for stellate cells (approximately -65 to $-70 \mathrm{mV}$ ), both currents inactivated with a similar time course.

The kinetics obtained in the voltage-clamp experiments lead to predictions on how $I_{\mathrm{A}}$ and $I_{\mathrm{T}}$ interact to produce the first-spike latency characteristics of stellate cells. The key factor in this process is expected to be the negatively shifted steady-state inactivation curve of $I_{\mathrm{T}}$ relative to $I_{\mathrm{A}}$. Two other contributing factors are expected to be the similar rates of $I_{\mathrm{A}}$ and $I_{\mathrm{T}}$ inactivation near spike threshold and the relative density of $I_{\mathrm{A}}$ versus $I_{\mathrm{T}}$. These properties would establish three key regions of membrane potential that could differentially modulate first-spike latency. The first region is spike firing immediately after a strong hyperpolarization $(-90$ to $-74 \mathrm{mV}$ ), in which sufficient $I_{\mathrm{T}}$ can be deinactivated to oppose $I_{\mathrm{A}}$. In the second region $(-74$ to $-70 \mathrm{mV})$, an intermediate hyperpolarization significantly inactivates more $I_{\mathrm{T}}$ than $I_{\mathrm{A}}$, thereby causing a long first-spike latency. Finally, after a weak or no hyperpolarization (less than $-70 \mathrm{mV}$ ), both $I_{\mathrm{A}}$ and $I_{\mathrm{T}}$ are inactivated, leading once again to a decrease in spike latency in direct relation to the membrane depolarization. By combining both $I_{\mathrm{A}}$ and $I_{\mathrm{T}}$, the stellate cell can achieve a nonmonotonic relationship between the first-spike latency and the preceding membrane voltage.

\section{A firing model using $I_{\mathrm{A}}$ and $I_{\mathrm{T}}$ reproduces stellate cell first- spike latency characteristics}

To further test our hypothesis that $I_{\mathrm{A}}$ and $I_{\mathrm{T}}$ can synergistically determine the first-spike latency characteristics of stellate cells, we built a reduced firing model incorporating their biophysical parameters. To simplify the model, we assumed that activation of both currents equilibrated with voltage instantaneously, which is reasonable considering that both currents activated very rapidly. Our model also incorporated a high ratio of $I_{\mathrm{A}}$ relative to $I_{\mathrm{T}}\left(I_{\mathrm{A}}\right.$, $\left.16 \mu \mathrm{S} / \mathrm{cm}^{2} ; I_{\mathrm{T}}, 0.55 \mu \mathrm{S} / \mathrm{cm}^{2}\right)$, which was within the values observed experimentally ( $g_{\max }$ for $I_{\mathrm{A}}, 1$ to 0.17 vs $g_{\max }$ for $I_{\mathrm{T}}, 0.1$ to 0.01 ; values normalized to $\left.I_{\mathrm{A}} g_{\max }\right)$. Finally, the inactivation time constant was fixed at $15 \mathrm{~ms}$, because the region of interest and the principal function for $I_{\mathrm{A}}$ and $I_{\mathrm{T}}$ is in the subthreshold region in which both currents showed similar inactivation time constants (Fig. $3 F$ ) (both ranged from 9 to $16 \mathrm{~ms}$ at $-60 \mathrm{mV}$ ). In addition to $I_{\mathrm{A}}$ and $I_{\mathrm{T}}$, the model incorporated a standard fast inactivating $\mathrm{Na}^{+}$and noninactivating $\mathrm{K}^{+}$current, the parameters of which 
A

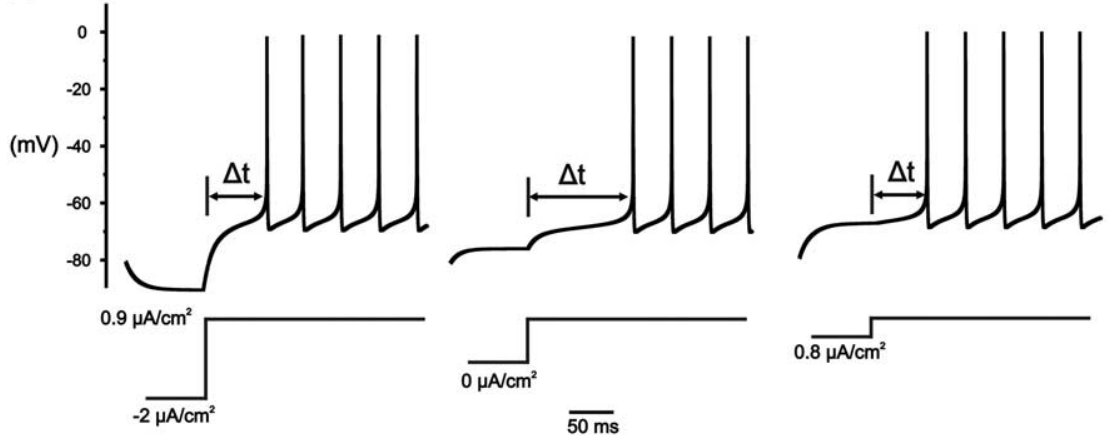

B

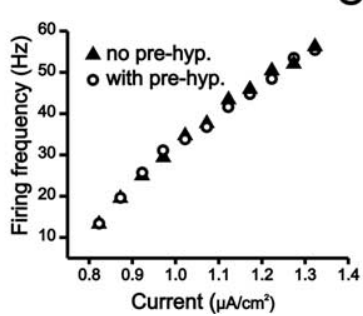

C

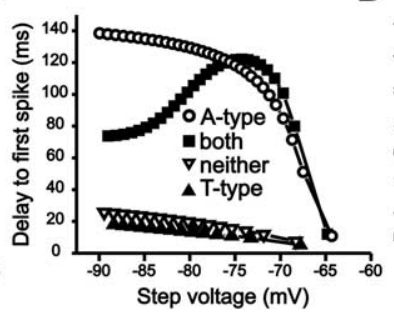

D

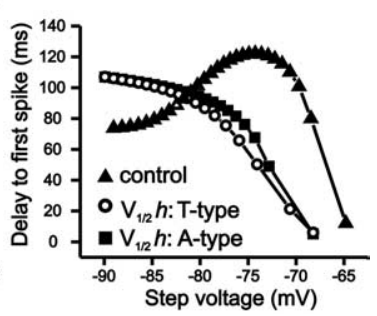

Figure 4. A model of a cerebellar stellate cell using the measured biophysical parameters of $I_{A}$ and $l_{T}$ reproduces spike latencyvoltage characteristics. $A$, Voltage trajectories in the model in response to different levels of hyperpolarization. The model was held with $-2 \mu \mathrm{A} / \mathrm{cm}^{2}$ (left), $0 \mu \mathrm{A} / \mathrm{cm}^{2}$ (middle), or $0.8 \mu \mathrm{A} / \mathrm{cm}^{2}$ (right) and followed by a step to $0.9 \mu \mathrm{A} / \mathrm{cm}^{2}$. Note that intermediate hyperpolarization produced the longest spike latency. $\boldsymbol{B}, \mathrm{F}-\mathrm{I}$ relationship in the model measured with no hyperpolarization (pre-hyp.) ( $(\boldsymbol{\Delta})$ or after a $-2 \mu \mathrm{A} / \mathrm{cm}^{2}$ hyperpolarizing current pulse $(\bigcirc)$. C, Spike latency-voltage relationship for stellate model cell in the presence of $I_{A}$ and $I_{T}(\boldsymbol{\square})$, with $I_{A}$ only $(O)$, $I_{T}$ only $(\mathbf{\Delta})$, or neither $I_{A}$ nor $I_{T}(\nabla)$. The model cell was stepped to $0.9 \mu \mathrm{A} / \mathrm{cm}^{2}$ after a current pulse of 90 ms duration that was varied in magnitude from -2 to $0.8 \mu \mathrm{A} / \mathrm{cm}^{2}$ in $0.1 \mu \mathrm{A} / \mathrm{cm}^{2}$ increments. The voltage in plot was measured immediately before stepping to $0.9 \mu \mathrm{A} / \mathrm{cm}^{2}$. Spike latency was measured from the end of the variable current step to the threshold of the first spike. $\boldsymbol{D}$, Spike latency-voltage relationship with different steady-state inactivation $V_{1 / 2}$ values for $I_{A}$ and $I_{T}$ compared with control. The inactivation $V_{1 / 2}$ of either $I_{A}$ or $I_{T}$ was shifted to abolish the differences in $V_{1 / 2}$ between the currents. In the first test, the inactivation $V_{1 / 2}$ of $I_{A}$ was matched to that of $I_{T}(-78 \mathrm{mV})(O)$, whereas in the second test, the $V_{1 / 2}$ of $I_{T}$ was matched to that of $I_{A}(-68 \mathrm{mV})(\square)$. Note that the coexpression of $I_{A}$ and $I_{T}$ with different inactivation voltages is required to invoke a nonmonotonic first-spike latency-voltage relationship.

were set to reproduce the spike shape of stellate cells and the firing frequency range over a $F-I$ plot $(5-50 \mathrm{~Hz})$.

The model had a current threshold for spiking of $0.83 \mu \mathrm{A} /$ $\mathrm{cm}^{2}$, which corresponded to a voltage threshold of approximately $-64 \mathrm{mV}$, which compared favorably with the threshold determined in stellate cells of $-58 \pm 1.4 \mathrm{mV}(n=14$; range, -51 to $-68 \mathrm{mV}$ ). When the model was depolarized to $0.9 \mu \mathrm{A} / \mathrm{cm}^{2}$ following a negative current injection of $-2 \mu \mathrm{A} / \mathrm{cm}^{2}$ it produced a spike latency of $74 \mathrm{~ms}$ (Fig. $4 A$, left). Using the same protocol but without negative current injection $\left(0 \mu \mathrm{A} / \mathrm{cm}^{2}\right)$, the model generated a longer latency of $122 \mathrm{~ms}$ (Fig. 4A). Finally, following a positive current injection of $0.8 \mu \mathrm{A} / \mathrm{cm}^{2}$, the model had a short latency with a value of $72 \mathrm{~ms}$ (Fig. $4 \mathrm{~A}$ ). The $F-I$ plot of the model was also similar to that of the stellate cell, with a relatively linear $F-I$ relationship that was insensitive to prehyperpolarization (-2 $\mu \mathrm{A} / \mathrm{cm}^{2}$ ) (Fig. $4 B$ ).

We quantified the first-spike latency-voltage relationship in the model by systematically applying a range of current injections that produced preceding membrane voltages between -90 and $-64 \mathrm{mV}$. In this way, we could assess the accuracy of the model with respect to the experimental results of Figure $1 C$. In the presence of both $I_{\mathrm{A}}$ and $I_{\mathrm{T}}$, we found that the model reproduced the experimental data, with a maximum delay of $130 \mathrm{~ms}$ following a membrane voltage of $-74 \mathrm{mV}$ and delays of 74 and $20 \mathrm{~ms}$ following voltages of -85 and $-65 \mathrm{mV}$, respectively. In the absence of $I_{\mathrm{T}}$, the influence of $I_{\mathrm{A}}$ in the model produced long first-spike latencies that increased in a monotonic manner with membrane hyperpolarization (Fig. 4C) and was thus similar to the experimental results in the presence of mibefradil (Fig. 2D). Conversely, the removal of $I_{\mathrm{A}}$ in the model increased firing frequency and almost entirely eliminated delays to first spike, with values ranging from 22 to $10 \mathrm{~ms}$ following membrane voltages from -90 to $-68 \mathrm{mV}$, respectively (Fig. 4C). Finally, the removal of both currents produced a slight increase in first-spike latency compared with $I_{\mathrm{T}}$ expression alone.

We note that the removal of $I_{\mathrm{A}}$ did not promote a rebound burst discharge in the model cell (data not shown), a result that matched experimental data in the presence of $6 \mathrm{~mm} 4$-AP (Fig. 2A,B). The lack of rebound burst discharge in the absence of $I_{\mathrm{A}}$ was because of two reasons. First, the stellate cell and model had relatively small amounts of $I_{\mathrm{T}}$ that inactivated very rapidly. Thus, $I_{\mathrm{T}}$ is sufficient to influence latency near spike threshold in which small and rapid changes in net current can substantially change the first-spike latency but is insufficient to produce an increase in firing frequency. Second, the removal of $I_{\mathrm{A}}$ significantly increased firing frequency both in the model and stellate cells $(>100$ $\mathrm{Hz}$ ), such that the system was operating near the maximum possible firing frequency even with the small depolarizing current injection presented after the hyperpolarization. Consequently, the recruitment of $I_{\mathrm{T}}$ with a strong hyperpolarization could not increase firing frequency, because the cell was in the saturated region of the $F-I$ relationship.

To test the hypothesis that the difference in steady-state inactivation curves between $I_{\mathrm{A}}$ and $I_{\mathrm{T}}$ was responsible for the firstspike latency-voltage relationship, we used the model to shift the $V_{1 / 2}$ inactivation values. In the first test, we shifted the inactivation $V_{1 / 2}$ of $I_{\mathrm{A}}$ to match that of $I_{\mathrm{T}}$, whereas in the second test, we shifted the inactivation $V_{1 / 2}$ of $I_{\mathrm{T}}$ to match that of $I_{\mathrm{A}}$ (Fig. $4 D$ ). Although there was a small shift in the firing threshold for the second test (because of the larger window current for $I_{\mathrm{T}}$ ), matching the $V_{1 / 2}$ of both currents prevented the longest first-spike latency from occurring at intermediate voltages and turned the latency-voltage relationship into a monotonically increasing function (Fig. 4D). This is because the cell expressed substantially larger amounts of $I_{\mathrm{A}}$ than $I_{\mathrm{T}}$. Matching the $V_{1 / 2}$ inactivation values thus removed any net increase in inward current that would result from hyperpolarizing the model cell more negative than $-75 \mathrm{mV}$, resulting in a net outward $\mathrm{K}^{+}$current. This result depended on the ratio of $I_{\mathrm{A}}$ to $I_{\mathrm{T}}$, such that reversing the relative density of these currents under conditions of identical $V_{1 / 2}$ for inactivation produced a bursting cell (data not shown). Finally, the similar rates of inactivation were necessary to allow $I_{\mathrm{T}}$ to offset the influence of $I_{\mathrm{A}}$ in delaying spike onset.

To test the above ideas, we measured the difference in peak activation between $I_{\mathrm{A}}$ and $I_{\mathrm{T}}$ during the conditioning hyperpolarizing step and plotted it against the membrane voltage during the step. For comparison, we have provided the steady-state inactivation curves for $I_{\mathrm{A}}$ and $I_{\mathrm{T}}$ used in the model and indicated the 
key voltage range of interest by dashed lines (Fig. 5A). As shown in Figure $5 B$, the maximum difference between the variables controlling $I_{\mathrm{A}}\left(h_{\mathrm{A}}\right)$ and $I_{\mathrm{T}}\left(h_{\mathrm{T}}\right)$ inactivation occurred at approximately $-74 \mathrm{mV}$, which also corresponded to the longest spike latency in the model (Fig. 4C). Moreover, by measuring the amount of the $h$ variable for $I_{\mathrm{A}}$ and $I_{\mathrm{T}}$ recruited per membrane voltage change in the conditioning prestep, we could quantify the sensitivity of each $h$ variable to membrane voltage $(d h / d V)$. With this analysis, a greater value indicates a greater sensitivity to membrane voltage, such that hyperpolarization greatly increases the net amount of available current. This test revealed that the $d h / d V$ curve for $I_{\mathrm{A}}$ started decreasing at more positive membrane voltages than $I_{\mathrm{T}}$ (Fig. $5 C$ ). Thus, $I_{\mathrm{T}}$ deinactivation continued to grow with more negative membrane voltages, whereas $I_{\mathrm{A}}$ began saturating (Fig. $5 \mathrm{~A}, \mathrm{C}$ ). Note that at intermediate voltages, the $d h / d V$ value for $I_{\mathrm{A}}$ is significantly greater than $I_{\mathrm{T}}$, which corresponded to the region of longest spike latencies in the model (Fig. 5C).

Our results show that first-spike latency characteristics of cerebellar stellate cells can be accounted for by the specific kinetic and steady-state properties of $I_{\mathrm{A}}$ and $I_{\mathrm{T}}$. The most critical factor is a left-shifted inactivation voltage for $I_{\mathrm{T}}$ compared with $I_{\mathrm{A}}$, with additional influence of a similar inactivation time constant for both currents near resting potential, and the relative density of expression.

Spike latency characteristics of stellate cells determine responses to coincident synaptic input

We next sought to test the interaction between $I_{\mathrm{A}}$ and $I_{\mathrm{T}}$ to consider its implications for synaptic integration. Stellate cells receive excitation from parallel fibers and inhibition from other stellate cells (Palay and Chan-Palay, 1974). In vitro dynamic-clamp experiments further indicate that stellate cells are optimized to process fast transient inputs (Suter and Jaeger, 2004), suggesting that first-spike latency effects may contribute significantly to modulating synaptically triggered spike firing in vivo. The effects of a nonmonotonic spike latency-voltage relationship would conceivably be most readily detected when EPSPs are immediately preceded by IPSPs. A study by Jorntell and Ekerot (2003) has shown, through in vivo patch recordings, that the baseline membrane potential of stellate cells can be shaped by EPSP and IPSP sequences with no apparent temporal pattern. In contrast, recent work has proposed that a feedforward inhibitory network can restrict synaptic activation of stellate cells to an EPSP-IPSP temporal sequence (Mittmann et al., 2005). It is unlikely that the mechanism we describe here would function within the context of feedforward inhibition. However, a randomly activated series of synaptic potentials could well act to trigger specific delays under conditions of an IPSP-EPSP sequence. We hypothesized that the nonmonotonic spike latency-voltage relationship could further alter the probability for spike firing after coincident inhibition, because this would make membrane voltage immediately before excitation more negative and thus reduce first-spike latency. To test this, we examined the effects of near coincident IPSP-EPSP responses in the model and in stellate cell recordings on the ability to trigger a spike.

Previous work has determined the kinetics of stellate cell EPSPs and IPSPs in vivo and has shown that there is a lack of heterogeneity of either EPSPs or IPSPs in terms of kinetics and peak amplitudes (Jorntell and Ekerot, 2003). The reversal potential of AMPA-mediated EPSPs is $0 \mathrm{mV}$, whereas that of $\mathrm{GABA}_{\mathrm{A}}$ mediated IPSPs is $-82.5 \mathrm{mV}$ (Carter and Regehr, 2002), with EPSPs exhibiting faster kinetics than those of IPSPs (Jorntell and
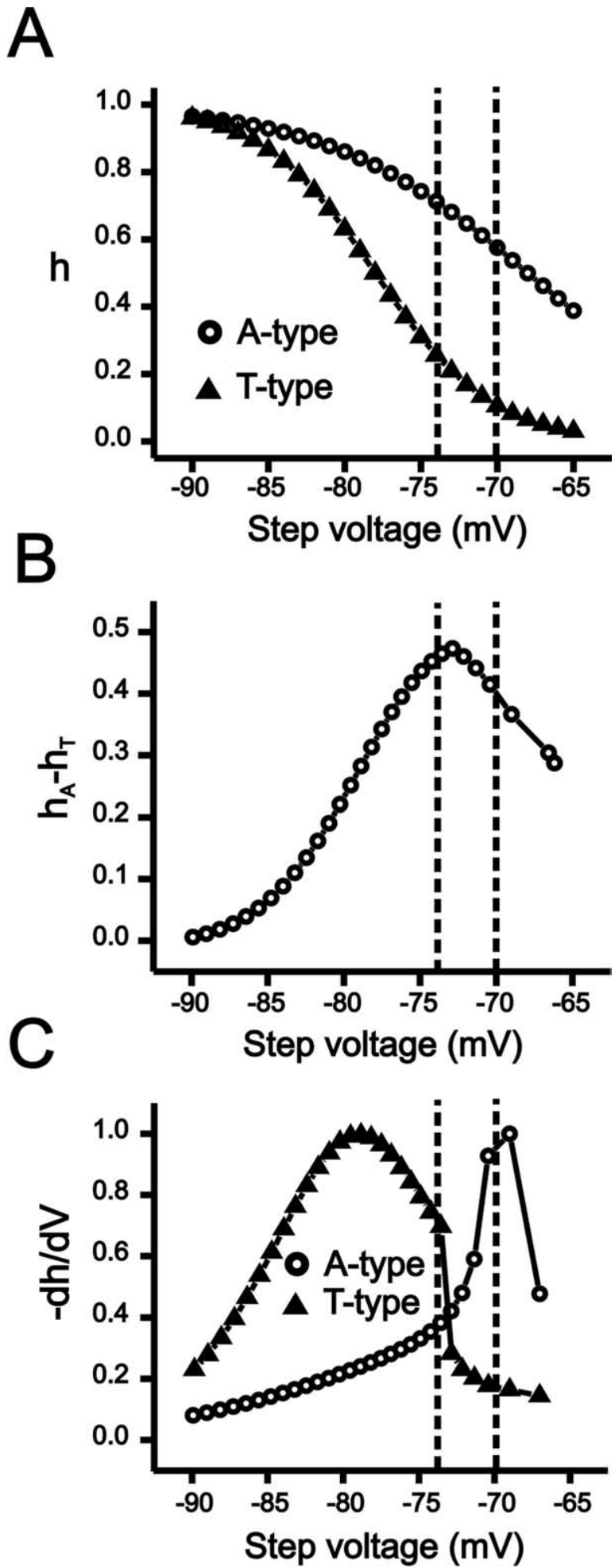

Figure 5. Spike latency is determined by subthreshold activation patterns of $I_{\mathrm{A}}$ and $I_{\mathrm{T}}$. $\boldsymbol{A}$, Steady-state inactivation fits from stellate cell model for $I_{\mathrm{A}}$ and $I_{\mathrm{T}}$. B, Differences in the magnitude of the variables controlling $I_{\mathrm{A}}\left(h_{\mathrm{A}}\right)$ and $I_{\mathrm{T}}\left(h_{\mathrm{T}}\right)$ inactivation in the model. Differences in the peak $h_{\mathrm{A}}$ and $h_{\mathrm{T}}$ during the conditioning prestep are plotted as a function of membrane voltage during the step. Note that the peak difference between $h_{\mathrm{A}}$ and $h_{\mathrm{T}}$ correspond to the voltage producing the longest spike latency. $C$, Comparison of the derivative of the peak available $I_{A}$ and $I_{\mathrm{T}}$ taken as the peak $h_{\mathrm{A}}$ and $h_{\mathrm{T}}$ values. Derivative values during the conditioning prestep are plotted as a function of membrane voltage during the step and normalized to the maximum rectified value. Note that the voltage region with the sharp drop in - $d h / d V$ for $I_{A}$ and an increase in $I_{\mathrm{T}}$ correspond to the peak delay in the model neuron. The dashed lines indicate the region of membrane potential that is associated with the longest delays in the model. 
A

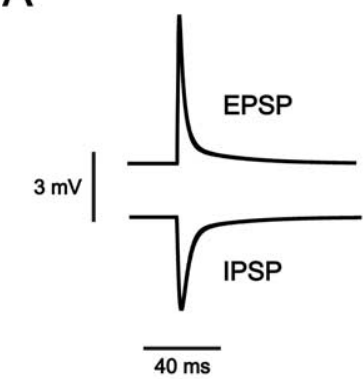

C
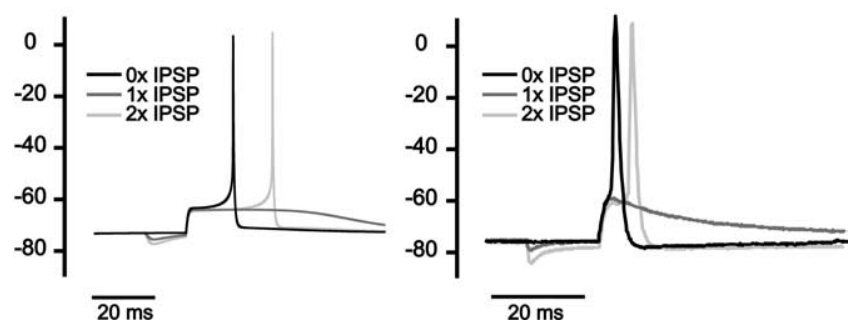

Figure 6. Implication of stellate cell spike latency characteristics for synaptic integration. $\boldsymbol{A}$, EPSP and IPSP waveforms used in the model at $-65 \mathrm{mV}$ membrane potential. Postsynaptic potential waveforms are based on kinetic properties of these responses in vivo and generated using an $\alpha$ function to describe synaptic conductances (see Materials and Methods), with reversals of $0 \mathrm{mV}$ for the EPSP and $-82 \mathrm{mV}$ for the IPSP. $\boldsymbol{B}$, Composite IPSP and EPSP waveforms in the model while holding at $-70 \mathrm{mV}$ and in the absence of spike-associated currents. The EPSP is applied with a 15 ms delay from the onset of the IPSP. C, Model (left) and stellate cell (right) response to composite postsynaptic potentials. The model cell was held at $-73 \mathrm{mV}$ with $0.3 \mu \mathrm{A} / \mathrm{cm}^{2}$, whereas the stellate cell was held between -68 and $-72 \mathrm{mV}$. Three forms of composite postsynaptic potentials were used. The first waveform consisted of the EPSP in isolation (black), whereas the second (dark gray) and third (light gray) were preceded by an IPSP with conductance multiplied by one and two, respectively (left). Note that the model and cell can fire a spike in the absence of an IPSP and with two coincident IPSPs but not with a single IPSP (dark gray).

Ekerot, 2003). To reproduce the EPSP and IPSP waveforms, we injected conductance waveforms into the model as $\alpha$-functions with parameters selected to match the in vivo characteristics reported by Jorntell and Ekerot (2003) (Fig. 6A). We then applied the EPSP in conjunction with different sizes of IPSPs to the model cell to examine the effects of coincident synaptic inputs on firstspike latency.

In the model, the EPSP presented alone attained a level of depolarization that was sufficient to reliably generate a single spike (Fig. 6C). We next applied the IPSP and EPSP in combination with the IPSP (peak voltage, $-73 \mathrm{mV}$ ) triggered $15 \mathrm{~ms}$ before the EPSP. When coupled with a preceding IPSP, the EPSP failed to generate a spike and simply depolarized the membrane voltage by $\sim 10 \mathrm{mV}$ (Fig. $6 C$ ). The inhibition of firing was not simply attributable to an algebraic summation of the IPSP and EPSP reducing overall EPSP amplitude, because the EPSP was reduced by $<0.5 \mathrm{mV}$. Moreover, a more slowly decaying EPSP of the same amplitude was sufficient to generate a spike when presented in conjunction with the IPSP (data not shown). We reasoned that the block of spike firing was attributable to an $I_{\mathrm{A}}$-mediated delay to first spike associated with the hyperpolarization evoked by the single IPSP. In fact, the $h_{\mathrm{A}}$ variable was increased by the IPSP from 0.068 to 0.71 . When we doubled the conductance underlying the IPSP to simulate two coincident inhibitory events (peak voltage, $-80 \mathrm{mV}$ ), the ability of the EPSP to generate a spike was restored (Fig. 6C). Note that this occurred despite a small decrease in EPSP peak amplitude but was associated with an in- crease in the $h_{\mathrm{T}}$ variable from 0.205 to 0.29 . Thus, the nonmonotonic latency-voltage relationship in stellate cells allows coincident IPSPs to promote spike firing by an EPSP by removing a delay to spike firing that otherwise dominates with a single IPSP.

To investigate this in the stellate cell, we applied the same conductance waveforms shown in Figure $6 A$ as current injection protocols (we reversed the inhibitory conductance to simulate inhibition) in the presence of synaptic blockers and adjusted the peak current injection values to produce similar IPSPs and EPSPs to those in the model. Although shunting could have an additional influence, we reasoned that the relatively negative $\mathrm{Cl}^{-}$ reversal potential of $-82.5 \mathrm{mV}$ would reduce this problem. Furthermore, Suter and Jaeger (2004) showed that in stellate cells, conductance injection with a dynamic-clamp setup did not produce substantially different results from direct current injection. As shown in Figure $6 D$, stellate cells were able to reproduce the model results, with single IPSP waveforms inhibiting spike firing by the EPSP, and coincident inhibition restoring spike firing. We tested this in seven cells and found that it could be evoked in all cells, although the reliability varied from 30 to $50 \%$. In the remaining cases, IPSPs were often more effective in inhibiting spike firing. Part of the variability was associated with the difficulties in maintaining a constant membrane voltage throughout the duration of the IPSP-EPSP waveform in a cell with such a high input resistance. Nevertheless, these experiments are sufficient to establish the potential for a nonmonotonic first-spike latency relationship to affect stellate cell output in response to membrane perturbations relevant to afferent input in vivo.

\section{Discussion}

The fast-inactivating class of $\mathrm{K}^{+}$channels is known to be involved in actively generating a delay to first spike by activating in the subthreshold region after hyperpolarization (Byrne et al., 1979; Storm, 1988; Kanold and Manis, 1999). Conversely, $I_{\mathrm{T}}$ has been generally implicated in generating rebound burst firing that is also promoted by a preceding hyperpolarization (Llinas and Jahnsen, 1982; Huguenard and Prince, 1992; Huguenard, 1996). We have shown that the coexpression of these two channels in stellate cells gives rise to a novel spike latency-voltage relationship, allowing preceding membrane hyperpolarizations to either reduce or lengthen the latency to first spike. Furthermore, we show that these interactions can be invoked by synaptic inputs inherent to stellate cells, indicating that this interaction will be effective in modulating the latency to discharge of stellate cells in vivo and hence their influence on Purkinje cell output.

Recordings and modeling indicate that first-spike latency in stellate cells is shaped by the coexpression, kinetic properties, and relative densities of $I_{\mathrm{A}}$ and $I_{\mathrm{T}}$. The presence of $I_{\mathrm{A}}$ allows moderate hyperpolarizations (more positive than $-72 \mathrm{mV}$ ) to invoke a well recognized increase in the delay to first spike. A nonmonotonic spike latency-voltage relationship arises as the result of $I_{\mathrm{T}}$ having a more negative steady-state inactivation curve relative to $I_{\mathrm{A}}$. Thus, spike latencies after strong hyperpolarizing steps (more negative than $-72 \mathrm{mV}$ ) can disproportionately recruit more $I_{\mathrm{T}}$ than $I_{\mathrm{A}}$ because of the negatively shifted inactivation curve of $I_{\mathrm{T}}$. This results in a net increase in inward current after depolarization that translates into a significant reduction in first-spike latency. This further illustrates that $I_{\mathrm{T}}$ can interact with other currents in the subthreshold region to function in roles outside of generating rebound burst firing. Finally, our model and recordings demonstrate that a nonmonotonic spike latency-voltage relationship can have important implications for synaptic integra- 
tion. In particular, the data indicate that even subtle increases in inhibitory coincidence can essentially reverse first-spike latencies and change the probability of firing in response to excitatory synaptic depolarizations.

\section{Low density of expression and fast inactivation kinetics of $I_{\mathrm{T}}$ preclude burst firing}

Stellate cells did not show rebound burst firing under physiological conditions. Even in the absence of $I_{\mathrm{A}}$, neither the cell nor model were able to produce rebound burst firing after strong hyperpolarizations. This result differs from a previous study that showed that the removal of $I_{\mathrm{A}}$ in thalamic interneurons, which also coexpress $I_{\mathrm{T}}$, could lead to rebound burst firing (Pape et al., 1994). $I_{\mathrm{T}}$ in stellate cells, however, differed from those recorded in thalamic cells in a few important aspects. First, stellate cells express relatively low levels of $I_{\mathrm{T}}$, especially when compared with $I_{\mathrm{A}}$. In thalamic interneurons, this ratio is more balanced (Pape et al., 1994). Second, $I_{\mathrm{T}}$ in stellate cells is faster to inactivate near firing threshold compared with thalamic neurons (Pape et al., 1994). Thus, the absence of rebound burst firing in stellate cells is likely a result of the inability of a small and rapidly inactivating $I_{\mathrm{T}}$ to evoke an increase in firing frequency. Furthermore, in the absence of $I_{\mathrm{A}}$, the cell had an intrinsic high firing frequency that was operating near the saturated region of the $F-I$ relationship. As a result, a small additional recruitment of $I_{\mathrm{T}}$ may not be able to significantly influence firing frequency resulting from the low gain (slope) in the $F-I$ relationship of the neuron in 4-AP.

\section{Potential molecular identity of $I_{\mathrm{A}}$ and $I_{\mathrm{T}}$}

We found that $I_{\mathrm{A}}$ in stellate cells was insensitive to TEA at concentrations of up to $20 \mathrm{~mm}$ but was sensitive to 4 -AP ( $>4 \mathrm{~mm}$ ). The lack of effect of TEA rules out the potential contribution of a number of A-type or inactivating $\mathrm{K}^{+}$currents of the $\mathrm{K}_{\mathrm{v}} 1$ or $\mathrm{K}_{\mathrm{v}} 3$ family (Coetzee et al., 1999). Rather, these results are consistent with members of the $\mathrm{K}_{\mathrm{v}} 4$ family, with stellate cells reportedly positive for at least $\mathrm{K}_{\mathrm{v}} 4.3$ immunolabel (Hsu et al., 2003). The biophysical parameters for $I_{\mathrm{A}}$ in stellate cells are also similar to those for $\mathrm{K}_{\mathrm{v}} 4$ channels in other central neurons as well as expression systems when $\mathrm{K}_{\mathrm{v}} 4$ subunits are coexpressed with the intracellular protein DPPX (dipeptidyl aminopeptidase-like protein) (Nadal et al., 2003). The activation $V_{1 / 2}$ of $\mathrm{K}_{\mathrm{v}} 4$ subunits are relatively positive $\left(V_{1 / 2}\right.$ more than $\left.-30 \mathrm{mV}\right)$, with shallow slope factors $(k>8)$ and a relatively negative and steep steady-state inactivation $\left(V_{1 / 2}\right.$ less than $-65 \mathrm{mV} ; k<6$ ) (Nadal et al., 2003). This compares very favorably to an activation $V_{1 / 2}$ of $-27 \mathrm{mV}$ $(k=10)$ and inactivation $V_{1 / 2}$ of $-68 \mathrm{mV}(k=5)$ for $I_{\mathrm{A}}$ recorded in stellate cells. The potential contribution of different $\mathrm{K}_{\mathrm{v}} 4$ subunits in producing this current are not currently known.

Previous in situ hybridization studies have not detected measurable levels of mRNA for $\mathrm{Ca}_{\mathrm{v}} 3 . \mathrm{x}$ calcium channel subtypes in cerebellar stellate cells (Craig et al., 1999; Kase et al., 1999; Talley et al., 1999). Nevertheless, our recordings of a nifedipineinsensitive, low-threshold, and fast-inactivating calcium current that is blocked by $500 \mathrm{~nm}$ mibefradil provides strong support for its identification as a current generated by channels of the $\mathrm{Ca}_{\mathrm{v}} 3$ family. Indeed, we now have immunocytochemical evidence for the expression of $\mathrm{Ca}_{\mathrm{v}} 3.2$ and $\mathrm{Ca}_{\mathrm{v}} 3.3$ channel subtypes in cerebellar stellate cells (M. Molineux, unpublished observations). Our measurements of $I_{\mathrm{T}}$ are also consistent with the biophysical parameters measured in some central neurons, such as thalamic relay neurons (Huguenard and Prince, 1992; McCormick and Huguenard, 1992; Huguenard, 1996). One notable difference is the slightly faster inactivation kinetics measured in stellate cells. It is difficult, however, to compare $\mathrm{Ca}_{\mathrm{v}} 3$ current kinetics recorded in different neuronal cell types or in expression systems given the lack of a full comparison of $\mathrm{Ca}_{\mathrm{v}} 3$ channel distributions and the potential for posttranslational modifications to contribute to the wide variety of biophysical parameters reported for $I_{\mathrm{T}}(\mathrm{Hu}-$ guenard, 1996; Perez-Reyes et al., 1998; McRory et al., 2001; Chemin et al., 2002).

\section{A single IPSP inhibits firing, and coincident IPSPs promote firing}

The activation of $I_{\mathrm{A}}$ is traditionally thought to delay first-spike latency, a result that can be induced with synaptic inhibition (Berman and Maler, 1998; Kanold and Manis, 2005). Because the first-spike latency-voltage relationship in stellate cells is nonmonotonic, our model and data suggest that interactions between EPSPs and IPSPs can be more complicated. We show that EPSPs following weak inhibition by single IPSPs can be effectively filtered to prevent spike firing by an $I_{\mathrm{A}}$-mediated delay in firstspike latency. However, we also show that stronger inhibition, which can result from coincident IPSPs, can overcome the filtering properties of $I_{\mathrm{A}}$ by recruiting more $I_{\mathrm{T}}$. This mechanism is particularly suited in stellate cells because of the relatively negative $\mathrm{Cl}^{-}$reversal potential of $-82.5 \mathrm{mV}$ (Carter and Regehr, 2002). The decrease in first-spike latency observed here occurs with premembrane voltages more negative than $-72 \mathrm{mV}$, which minimally requires that IPSPs reverse slightly more negative than this value. The control over spike latency by this mechanism proves to be substantial, in providing a range of mean latencies that span from 20 to $128 \mathrm{~ms}$ after a hyperpolarization. Previous studies reveal that even a single spike in stellate cells can have an important influence on Purkinje cells by delaying spike onset and reducing firing frequency (Hausser and Clark, 1997). The spike latency-voltage relationships presented here thus have significant potential to control cerebellar output. Given the complexity of cerebellar circuitry, the precise contribution that these interactions could have on cerebellar computation is not yet understood, but the current mechanism is likely to be a factor in establishing the temporal requirements expected for cerebellar output.

A previous study looking at parallel fiber activation and EPSP dynamics in Purkinje and stellate cells found that feedforward inhibition in stellate cells strongly influenced the precise spike timing in Purkinje cells (Mittmann et al., 2005). In that study, the EPSP in stellate cells preceded the IPSP. Hence, our mechanism of synaptic control of first-spike latency is unlikely to work under those conditions. We suggest that the mechanism of synaptic control of first-spike latency outlined in the present study will emerge during the activation of stellate cell receptive fields. In vivo recordings have shown conditions in which EPSPs and IPSPs may arrive in any sequence (Jorntell and Ekerot, 2003). The network activity that generates this form of synaptic response has not been established but could arise from the high degree of interconnectedness of stellate cells combined with parallel fiber activation (Kondo and Marty, 1998). In addition, the first-spike latency mechanism here could potentially modulate a feedforward inhibitory loop by affecting the precise timing of inhibition between stellate cells. The network activity that could take advantage of a nonmonotonic spike latency-voltage relationship thus remains to be determined. Nevertheless, our results identify a novel interaction between two transient currents that serves to modulate both the latency and probability for discharging a spike in stellate cells by excitatory synaptic inputs. 


\section{References}

Berman NJ, Maler L (1998) Interaction of $\mathrm{GABA}_{\mathrm{B}}$-mediated inhibition with voltage-gated currents of pyramidal cells: computational mechanism of a sensory searchlight. J Neurophysiol 80:3197-3213.

Byrne JH, Shapiro E, Dieringer N, Koester J (1979) Biophysical mechanisms contributing to inking behavior in Aplysia. J Neurophysiol 42:1233-1250.

Carter AG, Regehr WG (2002) Quantal events shape cerebellar interneuron firing. Nat Neurosci 5:1309-1318.

Chemin J, Monteil A, Perez-Reyes E, Bourinet E, Nargeot J, Lory P (2002) Specific contribution of human T-type calcium channel isotypes (alpha(1G), alpha(1H) and alpha(1I)) to neuronal excitability. J Physiol (Lond) 540:3-14.

Coetzee WA, Amarillo Y, Chiu J, Chow A, Lau D, McCormack T, Moreno H, Nadal MS, Ozaita A, Pountney D, Saganich M, Vega-Saenz de Miera E, Rudy B (1999) Molecular diversity of $\mathrm{K}^{+}$channels. Ann NY Acad Sci 868:233-285.

Craig PJ, Beattie RE, Folly EA, Banerjee MD, Reeves MB, Priestley JV, Carney SL, Sher E, Perez-Reyes E, Volsen SG (1999) Distribution of the voltagedependent calcium channel alphalG subunit mRNA and protein throughout the mature rat brain. Eur J Neurosci 11:2949-2964.

Ekerot CF, Jorntell H (2001) Parallel fibre receptive fields of Purkinje cells and interneurons are climbing fibre-specific. Eur J Neurosci 13:1303-1310.

Hausser M, Clark BA (1997) Tonic synaptic inhibition modulates neuronal output pattern and spatiotemporal synaptic integration. Neuron 19:665-678.

Heil P (2004) First-spike latency of auditory neurons revisited. Curr Opin Neurobiol 14:461-467.

Hoffman DA, Magee JC, Colbert CM, Johnston D (1997) $\mathrm{K}^{+}$channel regulation of signal propagation in dendrites of hippocampal pyramidal neurons. Nature 387:869-875.

Hsu YH, Huang HY, Tsaur ML (2003) Contrasting expression of Kv4.3, an A-type $\mathrm{K}^{+}$channel, in migrating Purkinje cells and other post-migratory cerebellar neurons. Eur J Neurosci 18:601-612.

Huguenard JR (1996) Low-threshold calcium currents in central nervous system neurons. Annu Rev Physiol 58:329-348.

Huguenard JR, Prince DA (1992) A novel T-type current underlies prolonged $\mathrm{Ca}^{2+}$-dependent burst firing in GABAergic neurons of rat thalamic reticular nucleus. J Neurosci 12:3804-3817.

Johansson RS, Birznieks I (2004) First spikes in ensembles of human tactile afferents code complex spatial fingertip events. Nat Neurosci 7:170-177.

Jorntell H, Ekerot CF (2002) Reciprocal bidirectional plasticity of parallel fiber receptive fields in cerebellar Purkinje cells and their afferent interneurons. Neuron 34:797-806.

Jorntell H, Ekerot CF (2003) Receptive field plasticity profoundly alters the cutaneous parallel fiber synaptic input to cerebellar interneurons in vivo. J Neurosci 23:9620-9631.

Kanold PO, Manis PB (1999) Transient potassium currents regulate the discharge patterns of dorsal cochlear nucleus pyramidal cells. J Neurosci 19:2195-2208.

Kanold PO, Manis PB (2005) Encoding the timing of inhibitory inputs. J Neurophysiol 93:2887-2897.

Kase M, Kakimoto S, Sakuma S, Houtani T, Ohishi H, Ueyama T, Sugimoto T (1999) Distribution of neurons expressing alpha $1 \mathrm{G}$ subunit mRNA of T-type voltage-dependent calcium channel in adult rat central nervous system. Neurosci Lett 268:77-80.

Kistler WM, van Hemmen JL, De Zeeuw CI (2000) Time window control: a model for cerebellar function based on synchronization, reverberation, and time slicing. Prog Brain Res 124:275-297.

Kondo S, Marty A (1998) Synaptic currents at individual connections among stellate cells in rat cerebellar slices. J Physiol (Lond) 509:221-232.
Llinas R, Jahnsen H (1982) Electrophysiology of mammalian thalamic neurones in vitro. Nature 297:406-408.

MacLean JN, Zhang Y, Johnson BR, Harris-Warrick RM (2003) Activityindependent homeostasis in rhythmically active neurons. Neuron 37:109-120.

McCormick DA, Huguenard JR (1992) A model of the electrophysiological properties of thalamocortical relay neurons. J Neurophysiol 68:1384-1400.

McDonough SI, Bean BP (1998) Mibefradil inhibition of T-type calcium channels in cerebellar Purkinje neurons. Mol Pharmacol 54:1080-1087.

McKay BE, Molineux ML, Mehaffey WH, Turner RW (2005) Kv1 K ${ }^{+}$channels control Purkinje cell output to facilitate postsynaptic rebound discharge in deep cerebellar neurons. J Neurosci 25:1481-1492.

McRory JE, Santi CM, Hamming KS, Mezeyova J, Sutton KG, Baillie DL, Stea A, Snutch TP (2001) Molecular and functional characterization of a family of rat brain T-type calcium channels. J Biol Chem 276:3999-4011.

Midtgaard J (1992a) Membrane properties and synaptic responses of Golgi cells and stellate cells in the turtle cerebellum in vitro. J Physiol (Lond) 457:329-354.

Midtgaard J (1992b) Stellate cell inhibition of Purkinje cells in the turtle cerebellum in vitro. J Physiol (Lond) 457:355-367.

Mittmann W, Koch U, Hausser M (2005) Feed-forward inhibition shapes the spike output of cerebellar Purkinje cells. J Physiol (Lond) 563:369-378.

Nadal MS, Ozaita A, Amarillo Y, Vega-Saenz de Miera E, Ma Y, Mo W, Goldberg EM, Misumi Y, Ikehara Y, Neubert TA, Rudy B (2003) The CD26-related dipeptidyl aminopeptidase-like protein DPPX is a critical component of neuronal A-type $\mathrm{K}^{+}$channels. Neuron 37:449-461.

Palay SL, Chan-Palay V (1974) Cerebellar cortex: cytology and organization. Berlin: Springer.

Pape HC (1996) Queer current and pacemaker: the hyperpolarizationactivated cation current in neurons. Annu Rev Physiol 58:299-327.

Pape HC, Budde T, Mager R, Kisvarday ZF (1994) Prevention of Ca(2+)mediated action potentials in GABAergic local circuit neurones of rat thalamus by a transient $\mathrm{K}^{+}$current. J Physiol (Lond) 478:403-422.

Perez-Reyes E, Cribbs LL, Daud A, Lacerda AE, Barclay J, Williamson MP, Fox M, Rees M, Lee JH (1998) Molecular characterization of a neuronal low-voltage-activated T-type calcium channel. Nature 391:896-900.

Russier M, Carlier E, Ankri N, Fronzaroli L, Debanne D (2003) A-, T-, and H-type currents shape intrinsic firing of developing rat abducens motoneurons. J Physiol (Lond) 549:21-36.

Schoppa NE, Westbrook GL (1999) Regulation of synaptic timing in the olfactory bulb by an A-type potassium current. Nat Neurosci 2:1106-1113.

Shibata R, Nakahira K, Shibasaki K, Wakazono Y, Imoto K, Ikenaka K (2000) A-type $\mathrm{K}^{+}$current mediated by the Kv4 channel regulates the generation of action potential in developing cerebellar granule cells. J Neurosci 20:4145-4155.

Storm JF (1988) Temporal integration by a slowly inactivating $\mathrm{K}^{+}$current in hippocampal neurons. Nature 336:379-381.

Suter KJ, Jaeger D (2004) Reliable control of spike rate and spike timing by rapid input transients in cerebellar stellate cells. Neuroscience 124:305-317.

Talley EM, Cribbs LL, Lee JH, Daud A, Perez-Reyes E, Bayliss DA (1999) Differential distribution of three members of a gene family encoding low voltage-activated (T-type) calcium channels. J Neurosci 19:1895-1911.

Thorpe S, Fize D, Marlot C (1996) Speed of processing in the human visual system. Nature 381:520-522.

Timmann D, Watts S, Hore J (1999) Failure of cerebellar patients to time finger opening precisely causes ball high-low inaccuracy in overarm throws. J Neurophysiol 82:103-114.

VanRullen R, Guyonneau R, Thorpe SJ (2005) Spike times make sense. Trends Neurosci 28:1-4. 